\title{
Specific Resistance Genes in Wheat Chinese Landrace 'Wangshuibai' against Two Iranian Mycosphaerella Graminicola Isolates
}

\author{
Reza Talebi (Corresponding Author) \\ Islamic Azad University -Sanandaj Branch, Iran
}

Sari Agricultural sciences and Natural Resources University, Sari, Iran

E-mail: srtalebi@yahoo.com

Mohsen Mardi

Agricultural Biotechnology Research Institute of Iran (ABRII), Karaj, Iran

E-mail: Mardi@abrii.ac.ir

Nadali babaeian Jelodar

Sari Agricultural sciences and Natural Resources University, Sari, Iran

E-mail:nbabaeian@yahoo.com

Mohammad Razavi

Plant Pests and Diseases Research Institute of Iran, Tehran, Iran

Seyed Mostafa Pirseyedi

Agricultural Biotechnology Research Institute of Iran (ABRII), Karaj, Iran

Gert Kema \& Rahim Mehrabi

Plant Research International, P.O. Box 16, 6700 AA Wageningen, the Netherlands

Mohsen Ebrahimi

Pardis University of Aboorayhan, Tehran, Iran

Thierry C Marcel

INRA-AgroParisTech, UMR1290 BIOGER-CPP, Avenue Lucien Brétignières BP01

78850 Thiverval-Grignon, France

This research is financed by Agricultural Biotechnology Research Institute of Iran (ABRII), Karaj, Iran.

\begin{abstract}
Septoria tritici blotch, caused by the fungus Mycosphaerella graminicola, is currently the major foliar disease of wheat world-wide, and new sources of resistance and knowledge about the genetics of resistance are needed to improve breeding for resistance against this disease. An $\mathrm{F}_{10}$ recombinant inbred population from a cross between 'Wangshuibai' (Chinese landrace) and the susceptible cultivar 'Seri82' was tested at seedling stage under controlled greenhouse conditions. Two isolate-specific genes for resistance to Iranian M.graminicola isolates IPO08002 and IPO08003 were detected on Chromosomes 2BL and 7DS, respectively. For both genes the resistance was derived from 'Wangshuibai' at positions where Stb9 (on 2BL) and Stb4 (on 7DS) have been
\end{abstract}


reported previously. These two genes are closely linked to microsatellite markers, which can be used for marker-assisted selection. 'Wangshuibai' may therefore be a valuable source of resistance to STB for wheat breeding, especially in Mediterranean environments.

Keywords: Disease resistance gene, Mycosphaerella graminicola, QTL mapping, Stb genes

\section{Introduction}

Mycosphaerella graminicola (anamorph Septoria tritici) causes septoria tritici blotch (STB), which is the most important disease of wheat in western Europe and other cereal production areas worldwide (Bearchell et al, 2005). The use of resistant cultivars reduces the necessity to apply costly fungicides treatments and is therefore an increasingly popular strategy for disease control. Consequently, wheat breeders have been selecting for resistance over the last three decades (Johnson, 1992). However, despite $15 \mathrm{Stb}$ genes have been mapped to date (Goodwin, 2007), the genetics of resistance and its phenotypic expression are still poorly understood. Specific interactions between wheat cultivars and M. graminicola isolates occur under both controlled seedling tests and field conditions (Kama et al. 1996, 1997; Brading et al, 2002). Hence, such specific interactions were shown to operate through a gene-for-gene mechanism (Kema et al, 2000; Brading et al. 2002). The breakdown of septoria tritici blotch resistances reported in Australia, Israel and the USA (Eyal et al, 1973; Ballantyne and Thomson, 1995; Cowger et al. 2000) is also consistent with the hypothesis of a gene-for-gene interaction and underlines the need for an improved understanding of this pathosystem. septoria tritici blotch resistance has been reported as either a qualitative (Wilson, 1979; Somasco et al, 1996; McCartney et al, 2002) or quantitative trait (Jlibene et al, 1994; Simon and Cordo, 1998). Pyramiding resistance genes involved in gene-for-gene interactions may provide durable resistance against septoria tritici blotch. Resistance gene pyramids can be developed by screening breeding populations for resistance to isolates with specific virulence patterns and/or with DNA-based markers linked to resistance genes. This is particularly useful when specific isolates are not available, when resistance genes are not sufficiently phenotypically distinguishable or when disease evaluations take place under suboptimal conditions for the disease. Fifteen Stb genes have been mapped. Nevertheless, the majority of commercial wheat cultivars is at least moderately susceptible to STB. Germplasm originating from China ('Synthetic 6x'), Latin America ('SO852') and Europe ('Arina', 'Shafir' and 'TE9111') were characterized as potential resistance sources (Arraiano et al, 2001, 2007; Chartrain et al, 2004; Adhikari et al, 2004), but several sources are not adapted to commercial breeding. We studied resistance to STB in 'Wangshuibai' that is widely used as a source of resistance to Fusarium Head Blight (FHB) (Mardi et al, 2005; Yu et al, 2008) and its common famous resistance sources in FHB breeding programs (Mardi et al, 2004). The objective of this study was to determine the chromosomal location of the STB resistance genes from 'Wangshuibai' and to identify linked simple sequence repeat (SSR) and/or amplified fragment length polymorphism (AFLP) markers, which can be applied in marker-assisted selection to improve STB resistance in wheat.

\section{Materials and Methods}

\subsection{Plant materials, inoculation procedure and disease assessment}

The $178 \mathrm{~F}_{10}$ RILs used in this study have been obtained from a cross between 'Wangshuibai', a resistant Chinese landrace of bread wheat, cv. 'Seri82' (Kavkaz/Buho- sib//Kalyansona/Bluebird) a susceptible Mexican spring bread wheat cultivar. The population was developed through single seed descent by Agricultural Biotechnology Research Institute of Iran (ABRII). The experiment was conducted in randomized complete design with three replicates over time. Five to 10 seeds per line were linearly sown in plastic pots $(5 \mathrm{by} 5 \mathrm{~cm})$ with a peat $/ \mathrm{sand}$ mixture. Plants were inoculated with two Iranian isolates designed IPO08002 and IPO08003 that were collected from Western (Kermanshah) and Southern (Darab) Iran that were selected according to a previous seedling phenotyping screen in the seedling stage, and differentiated both parents. Inoculum preparation, inoculations and disease assessments were performed as described elsewhere with slight modifications (Kema et al, 1996). The disease severity parameter was the percentage of the total primary leaf area covered by asexual fructifications of the fungus (pycnidia) and values were averaged per pot for further analyses.

\subsection{Genomic DNA extraction, AFLP and SSR markers}

Healthy leaves harvested from the parents ('Wangshuibai' and 'Seri82') and from the $178 \mathrm{~F}_{10}$ individual lines were used for DNA extraction. Total genomic DNA was isolated using a CTAB method with minor modifications (Saghai-Maroof et al. 1984). DNA quantity and quality were assessed with a UV-Photometer. The AFLP analysis was performed in a similar way to that described by Hartl et al. (1999) using the enzyme combination Sse8387I and MseI. Thirty Sse8387I+NN/MseI+NN primer combinations with two selective nucleotides on the 3 '-end of both primers were used for selective PCR amplification. Mapped SSR markers (Röder et al. 1998) were used to assign linkage groups to chromosomes. The parents 'Wangshuibai' and cv. Seri 
82 were tested for polymorphism with a total of 180 SSR primer pairs (Roeder et al. 1998) randomly according to their distribution, as described by Mardi et al. (2005) and polymorphic SSR primers were used for genotyping the entire population. The AFLP Sse8387I primer and the SSR forward primers were $5^{\prime}$ end-labeled with the fluorescent dye IRD-800 or IRD-700 (Fermentas, Germany). A DNA analyzer system (LI-COR 4200 DNA analyzer; Lincoln, NE, USA) was used to detect the amplified fragments as described by Mardi et al. (2005). The resulting images were printed and manually and independently scored.

\subsection{Construction of linkage map and QTL analysis:}

Linkage analysis was done using JOINMAP 2.0 (Stam and Van Ooijen 1995). Recombination fractions were converted into map distances by the Kosambi function (Kosambi 1944). The output from JOINMAP was converted to a graphical format using the program WinQTL 2.5 (Wang et al, 2007) and the QTL analysis was performed using the genotypic and phenotypic data from $\mathrm{F}_{10}$ RILs. Composite interval mapping (CIM) was performed to account for the masking effect of other QTLs on detected QTLs, using a stepwise regression analysis enabling additive genetic models and the selection of markers as cofactors to declare the presence of a putative QTL in a given genomic region. Finally, the location of a QTL was defined as a position where the LOD score value exceeds 2.5 based on permutation test.

\section{Results}

\subsection{Linkage map construction}

Thirty-six SSR primer pairs produced polymorphic bands and were used for genotyping the population. Analysis of the mapping population using polymorphic AFLP primer combinations resulted in 138 polymorphic bands with an average of 5.5 bands/primer pair. Out of the total 174 markers, 126 could be mapped, which resulted in 25 linkage groups, covering a genetic distance of $1031 \mathrm{CM}$.

\subsection{Segregation for disease resistance in the 'Wangshuibai' × 'Seri82' mapping population}

The inoculations resulted in excellent disease development in the parents and progeny in all experiments. 'Seri82' was very susceptible whereas 'Wangshuibai' was resistant to both isolates showing pycnidia percentages of $>70 \%$ and $<15 \%$, respectively. Transgressive segregation for resistance was observed in 29 and 8 lines RILs after inoculation with IPO08002 and IPO08003, respectively (Fig. 1). The low correlation $\left(\mathrm{R}^{2}=0.10\right)$ between responses to IPO08002 and IPO08003 confirmed that the observed resistance was isolate specific (Fig 2). Composite interval mapping using the existing map detected two QTLs. One with specificity to $M$. graminicola isolate IPO08002 on chromosome 2BL between microsatellite marker Xgwm526 and AFLP marker SA32 at $5.9 \mathrm{CM}$ and $11.02 \mathrm{CM}$, respectively (Table 1, Fig. 3). The other QTL with specificity for M. graminicola isolate IPO08003 mapped on chromosome 7DS between markers Xgwm437 and SA63 at $3.4 \mathrm{CM}$ and 6.6 CM, respectively (Table 1, Fig. 3).

\section{Discussion}

Resistance to STB is based on a quantitative assessment of the symptoms, the expression of which varies according to the variety, the aggressiveness of the isolates, and the environmental conditions (Gebhardt and Valkonen, 2001). For this reason, the establishment of a clear border differentiating resistant from susceptible genotypes is difficult. The detection of potential sources of resistance to M. graminicola and their genetic characterization are the first steps towards their utilization in practical breeding. In our pathology tests, the $F_{10}$ SSD population of 'Wangshuibai'/'Seri82' segregated for resistance to IPO08002 and IPO08003. For each isolate, the frequency distribution of disease severity indicated a continuous distribution with transgressive segregation. Consequently, we used QTL analysis software to identify the resistance components to STB in this population. The gene for resistance to M. graminicola IPO08002 on chromosome 2BL mapped close to the Xgwm526 locus, which is tightly linked to Xgwm317 that is at $10 \mathrm{CM}$ from the $\mathrm{Xtb} 9$ gene (Chartrain et al, 2009). This gene may also confer resistance to IPO08003 because, with the possible exception of few lines, all lines resistance to IPO08002 was also resistance to IPO08003. The other QTL on chromosome 7DS mapped close to the Xgwm437 locus, which is linked to Stb4 (Adhikari et al. 2004). This region also contains Stb5 as well as several genes for resistance to the Russian wheat aphid Diuraphis roxia (Liu et al, 2005). Therefore, the 7DS region may contain a cluster of resistance genes that could be interesting target for practical wheat breeding. Although we have not discovered new QTLs for STB resistance, it is good to know that 'Wangshuibai', which is one of the most important international sources for FHB resistance (Mardi et al, 2005; Yu et al, 2008), carries Stb4 and Stb9. Markers closely linked to these genes have been identified enabling their marker assisted selection from populations involving 'Wangshuibai'. Hence, deployment of this landrace and the identified markers enables simultaneous selection of STB and FHB resistant off spring. We also observed transgressive 
segregation for disease severity indicating that other factors may also contribute to STB resistance, but these were not significantly detected in additional QTLs. 'Wangshuibai' has resistance to STB controlled by isolate-specific genes in seedling stage. Results from previous investigations suggested that 'pyramiding' genes for resistance may be useful in breeding to develop varieties with excellent resistance to STB (Chartrain et al, 2004a). It is however difficult to say whether durable resistance to STB can be achieved by pyramiding many genes or by specific combination of particular resistance genes (McDonald and Linde, 2002). It is possible that some of the genes identified in 'Wangshuibai' have a greater contribution to field resistance than others. The Stb6 gene, for example, has been identified in most major sources of resistance to STB suggesting that it probably contributes to field resistance (Kema et al, 1997; Chartrain et al, 2005). The combination of several quantitative resistance genes is necessary to achieve a high level of STB resistance in a wheat genotype. Therefore, improvement for STB resistance should be made by combining resistance genes from different sources and simultaneous selection for resistance and desirable agronomic traits. In this study, QTL analysis of STB resistance of the Chinese landrace 'Wangshuibai' led to the detection of QTLs on chromosomes 2BL and 7DS that can be used in marker-assisted selection to improve STB resistance in wheat.

\section{References}

Adhikari, T.B., Anderson, J.M. \& Goodwin, S.B. (2003). Identification and molecular mapping of gene in wheat conferring resistance to Mycosphaerella graminicola. Phytopathology, 93: 1158-64.

Adhikari, T.B., Cavaletto, J.R., Dubcovsky, J., Gieco, J.O., Schlatter, A.R. \& Goodwin, S.B. (2004a). Molecular mapping of the Stb4 gene for resistance to septoria tritici blotch in wheat. Phytopathology, 94: 1198-206.

Adhikari, T.B., Yang, X., Cavaletto, J.R., Hu, X., Buechley, G. \& Ohm, H.W. (2004b). Molecular mapping of Stb1, a potentially durable gene for resistance to septoria tritici blotch in wheat. Theoretical and Applied Genetics, 109: 944-53.

Adhikari, T.B., Wallwork, H. \& Goodwin, S.B. (2004c). Microsatellite markers linked to the Stb2 and Stb3 genes for resistance to septoria tritici blotch in wheat. Crop Science, 44: 403-11.

Arraiano, L.S., Chartrain, L., Bossolini, E., Slatter, H.N., Keller, B. \& Brown, J.K.M. (2007). A gene in European wheat cultivars for resistance to an African isolate of Mycosphaerella graminicola. Plant Pathology, 56: $73-8$.

Arraiano, L.S., Worland, A.J. \& Brown, J.K.M. (2001). Chromosomal location of a gene for resistance to septoria tritici blotch (Mycosphaerella graminicola) in the hexaploid wheat Synthetic 6x. Theoretical and Applied Genetics, 103: 758-64.

Ballantyne, B. \& Thomson, F. (1995). Pathogenic variation in Australian isolates of Mycosphaerella graminicola. Australian Journal of Agricultural Research, 46:921-934.

Brading, P.A., Verstappen, E.C.P., Kema, G.H.J. \& Brown, J.K.M. (2002). A gene-for-gene relationship between wheat and Mycosphaerella graminicola, the septoria tritici blotch pathogen. Phytopathology, 92: $439-45$.

Bearchell, S.J., Fraaije, B.A., Shaw, M.W. \& Fitt, B.D.L. (2005). Wheat archive links longterm fungal pathogen population dynamics to air pollution. Proceeding of Natural Academic Sciences, USA, 102: 5438-5442.

Chartrain, L., Brading, P.A., Makepeace, J.C. \& Brown, J.K.M. (2004). Sources of resistance to septoria leaf blotch and implications for wheat breeding. Plant Pathology, 53: 454-60.

Chartrain, L., Berry, S.T. \& Brown, J.K.M. (2005a). Resistance of wheat line Kavkaz-K4500 L.6.A.4 to septoria tritici blotch controlled by isolate-specific resistance genes. Phytopathology, 95: 664-71.

Chartrain, L., Joaquim, P., Berry, S.T., Arraiano, L.S., Azanza, F. \& Brown, J.K.M. (2005b). Genetics of resistance to septoria tritici blotch in the Portuguese wheat breeding line TE 9111. Theoretical and Applied Genetics, 110: 1138-44.

Chartrain, L., Sourdill, P., Bernard, M. \& Brown, J.K.M. (2009). Identification and location of Stb9, a gene for resistance to septoria tritici blotch in wheat cultivar Courtot and Tonic. Plant Pathology, 58: 547-555.

Cowger, C., Hoffer, M.E. \& Mundt, C.C. (2000). Specific adaptation by Mycosphaerella graminicola to a resistant wheat cultivar. Plant Pathology, 49: 445-51.

Eyal, Z., Amiri, Z. \& Wahl, L. (1973). Physiologic specialization of Septoria tritici. Phytopathology, 63: 1087-1091. 
Gebhardt, C. \& Valkonen, J.P.T. (2001). Organization of genes controlling disease resistance in the potato genome. Annual Review of Phytopathology, 39: 79-102.

Goodwin, S.B. (2007). Back to basics and beyond: increasing the level of resistance to Septoria tritici blotch in wheat. Australian Plant pathology, 36: 532-538.

Hartl, L., Mohler, V., Zeller, F.J., Hsam, S.L.K. \& Schweizer, G. (1999). Identification of AFLP linked to the powdery mildew resistance genes Pm1c and Pm4a in common wheat (Triticum aestivum). Genome, 42: $322-329$.

Johnson, R. (1992). Past, Recent and future opportunities in breeding for disease resistance, with examples from wheat. Euphytica, 63: 3-22.

Jlibene, M., Gustafson, J.P. \& Rajaram, S. (1994). Inheritance of resistance to Mycosphaerella graminicola in hexaploid wheat. Plant Breeding, 112: 301-10.

Kema, G.H.J., Annone, J.G., Sayoud, R., van Silfhout, C.H., van Ginkel, M. \& deBree, J. (1996). Genetic variation for virulence and resistance in the wheat Mycosphaerella graminicola pathosystem. I. Interactions between pathogen isolates and host cultivars. Phytopathology, 86: 200-12.

Kema, G.H.J. \& van Silfhout, C.H. (1997). Genetic variation for virulence and resistance in the wheat Mycosphaerella graminicola pathosystem. III. Comparative seedling and adult plant experiments. Phytopathology, 87:266-72.

Kema, G.H.J., Verstappen, E.C.P. \& Waalwijk, G. (2000). Avirulence in the wheat septoria tritici leaf blotch fungus Mycosphaerella graminicola is controlled by a single locus. Molecular Plant Microbe Interaction, 13: $1375-9$.

Kosambi, D.D. (1944). The estimation of map distances from recombination values. Annual Eugen, 12:172-175.

Liu, X.M., Smith, C.M., Friebe, B.R. \& Gill, B.S. (2005). Molecular mapping and allelic relationships of Russian wheat aphid-resistance genes. Crop Science, 45: 2272-80.

Mardi, M., Buerstmayr, H., Ghareyazie, B., Lemmens, M., Mohammadi, S.A., Nolz, R. \& Ruckenbauer, P. (2005). QTL analysis of resistance to Fusarium head blight in wheat using a Wangshuibai-derived population. Plant Breeding, 124: 329-333.

Mardi, M., Ghareyazie, B., Buerstmayr, H., Lemmens, M., Moshrefzadeh, N. \& Ruckenbauer, P. (2004). Combining ability analysis of resistance to head blight caused by Fusarium graminearum in spring wheat. Euphytica, 139: 45-50.

McCartney, C.A., Brûlé-Babel, A.L. \& Lamari, L. (2002). Inheritance of race-specific resistance to Mycosphaerella graminicola in wheat. Phytopathology, 92: 138-44.

McDonald, B.A. \& Linde, C. (2002). Pathogen population genetics, evolutionary potential, and durable resistance. Annual Review of Phytopathology, 40: 349-379.

Röder, M.S., Korzun, V., Wendehake, K., Plaschke, J., Tixier, M.H. \& Leroy, P. (1998). A microsatellite map of wheat. Genetics, 149: 2007-2023.

Saghai-Maroof, M.A., Soliman, K., Jorgensen, R.A. \& Allard, R.W. (1984). Ribosomal DNA spacer-length polymorphisms in barley: mendelian inheritance, chromosomal location, and population dynamics. Proceeding of Natural Academic Sciences, USA, 81: 8014-8018.

Simon, M.R. \& Cordo, C.A. (1998). Diallel analysis of four resistance components to Septoria tritici in six crosses of wheat (Triticum aestivum). Plant Breeding, 117: 123-6.

Somasco, O.A., Qualset, C.O. \& Gilchrist, D.G. (1996). Single-gene resistance to septoria tritici blotch in the spring wheat cultivar Tadinia. Plant Breeding, 115: 261-7.

Stam, P. \& van Ooijen, J.W. (1995). JoinMap Version 2·0: Software for the Calculation of Genetic Linkage Maps. Wageningen, Netherlands: CPLO-DLO.

Wilson, R.E. (1979). Resistance to Septoria tritici in two wheat cultivars, determined by independent, single dominant genes. Australian Journal of Plant Pathology, 8: 16-18.

Xu, S., Zhang, Z., Lin, F., Kong, Z., Cao, Y. \& Li, C. (2008). A high-density intervarietal map of the wheat genome enriched with markers derived from expressed sequence tags. Theoretical and Applied Genetics, 17:181-189. 
Yu, J.B., Bai, G.H., Zhou, W.C., Dong, Y.H. \& Kolb, F.L. (2008). Quantitative trait loci for fusarium head blight resistance in a recombinant inbred population of Wangshuibai/Weaton. Phytopathology, 98: 87-94.

Table 1. Summary of QTL analyses for resistance to septoria leaf blotch detected on seedlings of the 'Wangshuibai' $x$ 'Seri82' wheat population against two the Iranian isolates IPO08002 and IPO08003. QTL analysis was carried out by composite interval mapping (CIM)

\begin{tabular}{lllll}
\hline Mg isolates & Confidence interval & Chrom. & LOD & VE \\
\hline IPO08002 & Xgwm526/SA32 & 2BL & 2.9 & 12.76 \\
IPO08003 & Xgwm437/SA63 & 7DS & 3.1 & 16.77 \\
\hline
\end{tabular}
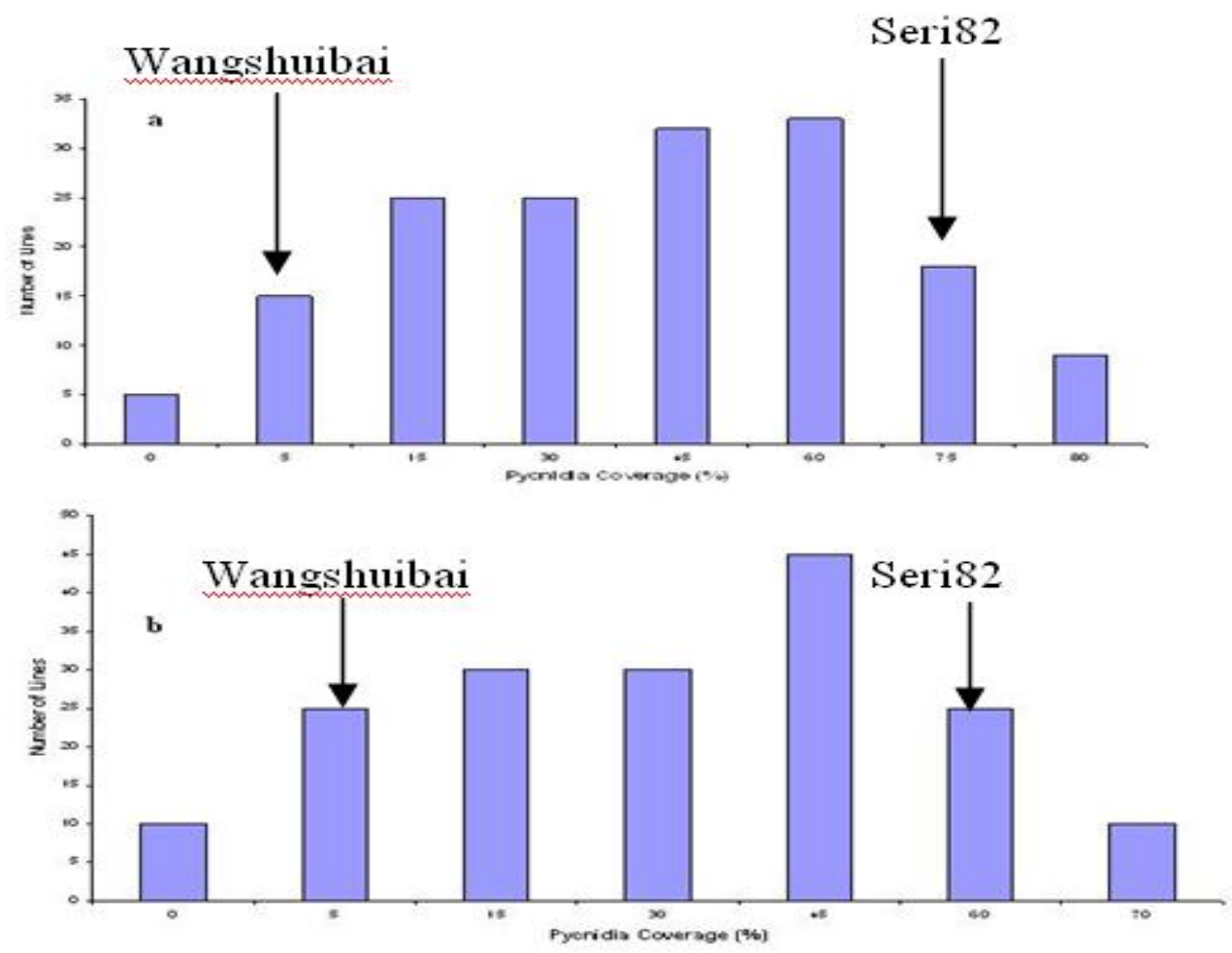

Figure 1. Segregation of resistance to Mycosphaerella graminicola isolates IPO08002 (a) and IPO08003 (b) in $\mathrm{F}_{10}$ SSD lines of a cross between the Chinese landrace 'Wangshuibai' and cv. 'Seri82'. The number of $\mathrm{F}_{10}$ SSD lines is plotted against the percentage of leaf area covered with pycnidia 


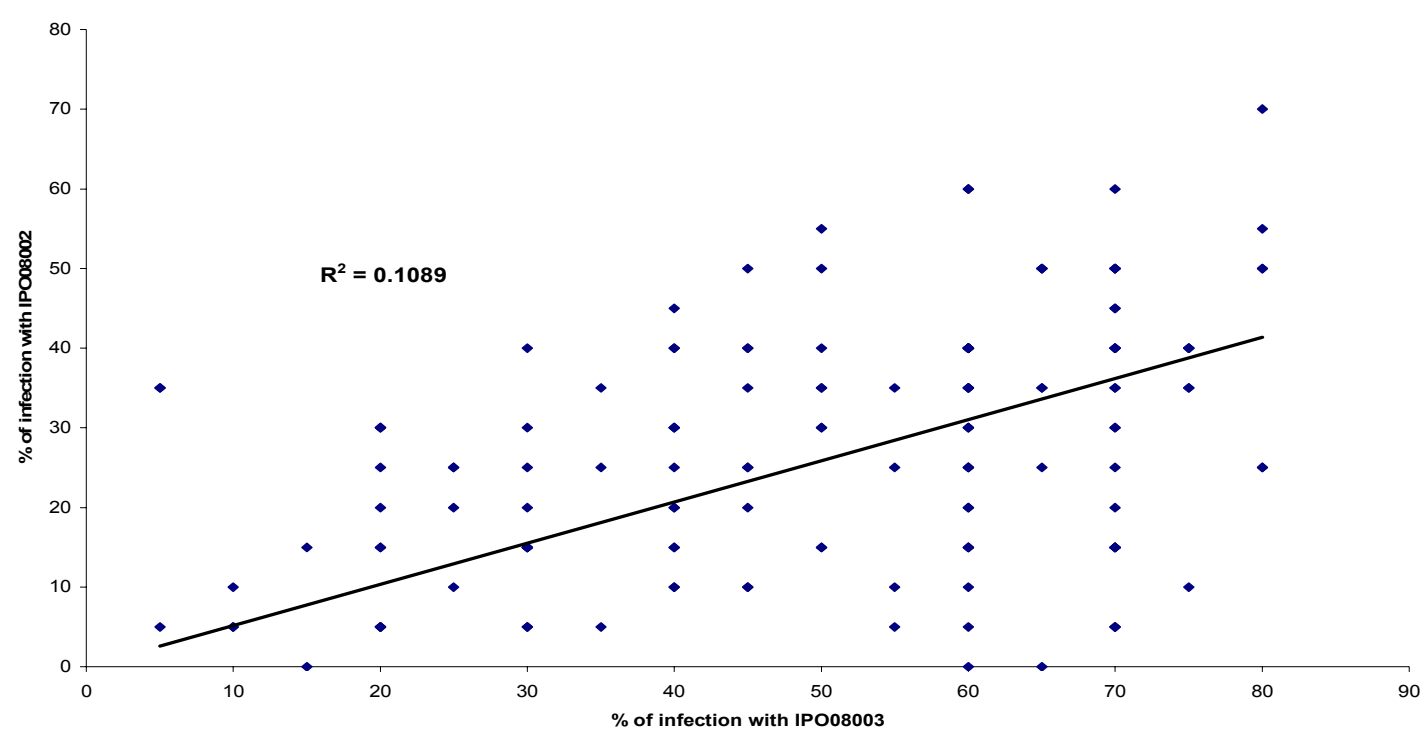

Figure 2. Correlation between infections caused by the two Iranian isolates IPO08002 and IPO08003 of Mycosphaerella graminicola. Percentage of leaf area covered by pycnidia of $\mathrm{F}_{10}$ SSD lines of 'Wangshuibai' $\times$ 'Seri82' with pairs of isolates. Both axes are logic scaled 


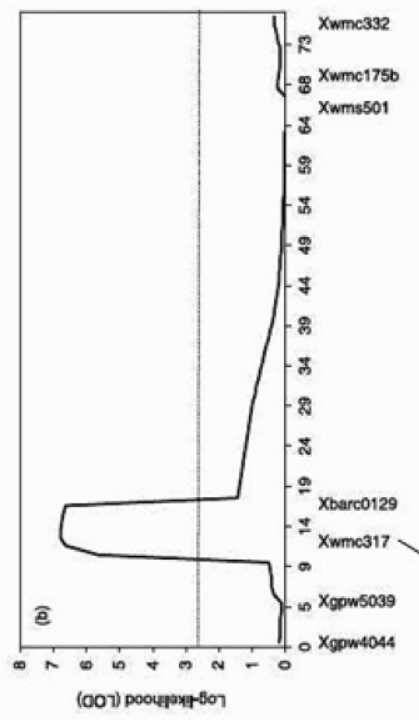

Chartrain et al., 2009

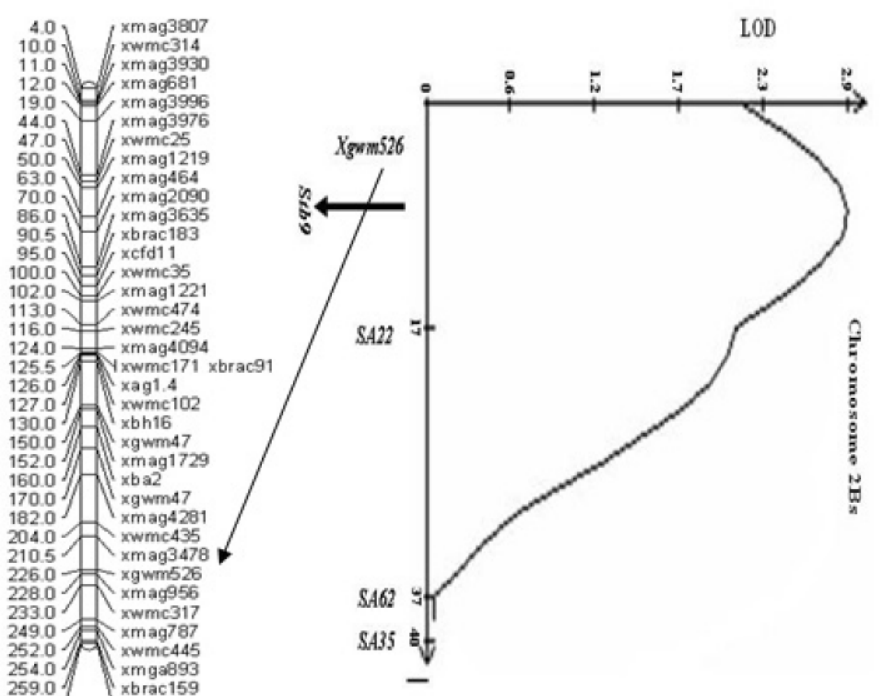

Xuet al., 2008

(a)

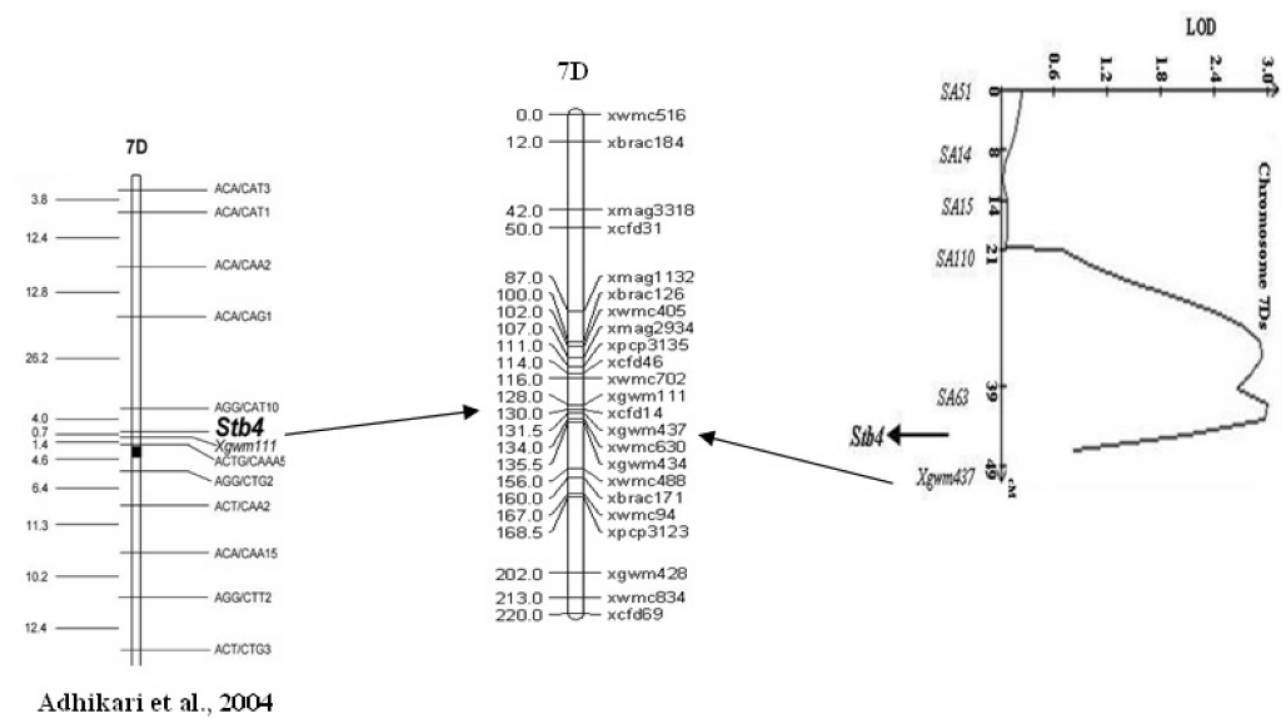

Xu et al., 2008

(b)

Figure 3. LOD profiles of QTL for resistance to Mycosphaerella graminicola against isolates IPO08002 (a) and IPO08003 (b) in the wheat $\mathrm{F}_{10}$ population derived from a cross between the Chinese landrace 'Wangshuibai' and cv. 'Seri82', detected by composite interval mapping (CIM) plotted against map distances 